\title{
THE SENSE AND MEANING ASCRIBED TO PROFESSIONAL WORK BY WOMEN WITH CANCER
}

\author{
Małgorzata Rębiałkowska-Stankiewicz \\ Kazimierz Wielki University in Bydgoszcz, Bydgoszcz, Poland \\ Faculty of Pedagogy and Psychology, Chair of Childcare Education and Social Prevention
}

\begin{abstract}
Background: The fact that professional activity is reduced is a very challenging experience for persons with cancer whose sense of self-worth is linked to their work. Not only does cancer often become the reason for their deteriorated socio-economic position but it also reduces the quality of life assessment in cancer patients. Material and Methods: The aim of the study was to discover the sense and meaning that women with cancer ascribe to their professional work. The research was carried out among 6 women diagnosed with cancer, aged 32-49 years. A qualitative research strategy was adopted in the study and interpretative phenomenological analysis was applied. Results: Based on the conducted research, when faced with cancer, the respondents often perceive professional work as a factor that triggers cancer and, at the same time, one that can increase their self-esteem, giving meaning to their life. It, therefore, seems crucial to support the professional activity of cancer patients and to create jobs promoting health. Conclusions: When working with a person suffering from cancer, it is worth considering the possibilities that returning to work is likely to carry. It is important to create such jobs and work environments that would be consistent with the concept of health promotion. It seems that the key factors here are the appointment of persons responsible for the return process of a person with a chronic illness, accompanied by efficient communication between the employer and occupational health services, and efficient exchange of information between the treating physician and the workplace (with the employee's consent). Med Pr. 2021;72(1):1-8
\end{abstract}

Key words: quality of life, cancer, women, chronic illness, professional work, role of the patient

Corresponding author: Małgorzata Rębiałkowska-Stankiewicz, Kazimierz Wielki University in Bydgoszcz, Faculty of Pedagogy and Psychology, Chair of Childcare Education and Social Prevention, Chodkiewicza 30, 85-064 Bydgoszcz, Poland, e-mail:malstan@wp.pl

Received: February 17, 2020, accepted: August 28, 2020

\section{INTRODUCTION}

The term "cancer" covers over a hundred different and separate disease entities with different etiology, and varying treatment protocols and clinical course [1] The course that is so characteristic of cancer and the invasive methods of treatment used have led to it being treated as a serious chronic disease [2]. In defining the term "illness", its socio-cultural dimension in relation to the "way in which the symptoms of cancer and disability are perceived, living with them, and reacting to them by the patient, family members or broader social network" is assumed [3]. When analyzing the concept of a "chronic illness," attention should be paid to the fact that the difficulties in developing an accurate definition are associated with it being a vague term, the scope of which is hard to define precisely.

One of the earliest definitions coined by the Commission on Chronic Illness states that a chronic illness includes "all impairments or deviations from normal that include one or more of the following: permanency; residual disability; non-pathologic alteration; required rehabilitation; or a long period of supervision, observation, and care" [4]. The definition of the World Health Organization dated 2002 has a simpler form and is limited to indicating that chronic illnesses are those "health problems that require an ongoing management over a period of years or decades" [5].

According to Twaddle and Hessel [6], in the situation of chronic, incurable illnesses when there are no grounds to expect recovery, the basic problem of patients is adapting to the new situation. In the discussion concerning the adequacy of the concept of an ill person experiencing a chronic illness, the main thread concerns the temporal criterion, namely, the duration of the health disorder. Attention is paid to the fact that a chronic illness is drawn out over time and implicates living with the disease; therefore, it cannot be interpreted in light of a concept that describes a normative pattern of social activity, which is somewhat interim and 
emergency in nature, and geared towards counteracting the adverse effects of the illness for the functioning of the society. Therefore, a key issue for the foregoing consideration emerges here, namely, whether the aim that is inherent to the role of a patient, concerning returning to their "normal social functioning," may be achieved in the situation of a chronic illness.

Every person suffering from cancer faces many challenges that accompany the disease. Adopting the role of "being a cancer patient" is associated with the necessity of verifying one's capabilities to date, reconsidering the values held dear thus far, changing life goals, and giving up plans, including those concerning professional life. During disease remission, what is important is returning to one's work and pastime activities, because not only is work a source of income for the patient but it also facilitates improving the assessment of their quality of life [7]. Pietrzyk [8] emphasized the fact that reduced professional activity is a heavy burden for patients whose sense of self-worth is associated with their professional work; thus, cancer becomes a destructor of their status and socio-economic position. According to the data of the National Cancer Registry at the Oncology Centre in Warsaw, over half of women diagnosed with cancer are aged 20-59 years and, thus, are professionally active [9]. Discovering the meaning ascribed to professional work by women with cancer and of reproductive age seems to be crucial for both social and individual reasons, given especially that the issue of returning to work concerns $60 \%$ of persons with cancer.

According to the research by Tamminga et al. [10], the process of returning to work is affected by the following factors associated with the work environment: support from a supervisor and colleagues, and the physical or psychological burden linked to the occupation. Among the barriers related to going back to work, the authors listed the personality of a person with cancer, and the "block" against taking up work (various types of anxiety linked to returning to pre-illness functioning, which may contribute to health deterioration). Other factors include the lack of information support from physicians, and specifically indications relating to the promotion of healthy behaviors at work, for them, their supervisors, and colleagues.

According to Danish studies carried out in 2019 in a group of 32 women with cancer, the perception of professional work changes after cancer treatment. Many respondents want to go back to work but, at the same time, are not ready to take on the same professional responsibilities they had before falling ill. Women also mention the lack of understanding for their health situation and the lack of support in the work environment [11].

The research by Mazurkiewicz [12] demonstrated the following tendencies among women after mastectomy on the labor market: younger women want to go back to work; women being white-collar workers have a greater chance of taking up work after their illness, while professionally unqualified women and women aged $>50$ years have meager chances. The surveyed women paid attention to signs of discrimination, for instance, in the form of being transferred to a different job, being recommended to claim disability benefits, and not getting the understanding or support from colleagues and employers.

\section{MATERIAL AND METHODS}

The research was carried out in the wards of the Fight Cancer Academy (FCA) in Torun, established in 2005. The aim of the FCA activities is to support oncology patients and their families through Simonton's therapy [13]. Support to persons with all types of cancer, and at different stages, is provided through both individual counseling and group work.

The aim of the presented study was to discover the sense and meaning that women with cancer ascribe to professional work. The formulated research objective is strictly connected with the interpretative paradigm. Interpretative phenomenological analysis (IPA) was applied, the subject of interest of which was the situation of a person, how they coped in the world, and the problems they experienced [14]. This approach can be applied within a qualitative research strategy. Thus, the overarching aim of IPA researchers is an in-depth and insightful analysis of how people make sense of, and give meaning to, their experiences [15]. This approach enables an analysis of smaller groups ( $\leq 6$ persons), and the aim of the research is not to develop a theory but to carry out a thorough and precise analysis of a given phenomenon, and to gain in-depth insight into the experience.

A semi-structured in-depth interview was carried out among the respondents. The questions concerned earlier experiences relating to professional work, the significance of work in their life, the emotions accompanying the need to give up work during their illness, and the problems associated with taking up work after treatment. The questions were asked in the same order for each participant. Auxiliary questions were asked where necessary. The surveyed women 
were given the opportunity to respond freely to the questions asked. The research was carried out in October 2019 among 6 women after cancer treatment, aged 22-49 years, who were participants in group activities at the FCA. The respondents were actively working when they fell ill. For 5 of them, the time from the diagnosis until the present ranged 1.5-3 years. Only 1 woman had been living with cancer for 12 years and still undergoing treatment. Three of the respondents had completed their treatment, 2 women were undergoing hormone therapy, and 1 was taking oral chemotherapy. The characteristics of the respondents are presented hereunder:

Respondent 1 (Edyta): 32 years old, with higher education, married with 2 children; endometrial cancer, treated with hormone therapy; working as a civil servant for half a year; 2 years since completing treatment.

Respondent 2 (Violetta): 47 years old, with higher education, single, a single mother of a son; breast cancer, treated with hormone therapy; held a managerial position in a corporation before falling ill; currently looking for work; 1.5 years since completing treatment.

Respondent 3 (Anna): 42 years old, with higher education, married with 2 children; lymphoma, treatment completed; worked as a shop assistant before being diagnosed with cancer; after completing treatment, worked half a year in the same line of work; currently out of work; 2 years since completing treatment.

Respondent 4 (Zofia): 36 years old, with higher education, married; thyroid tumor; not working since the diagnosis (10 years ago); previously employed as a telemarketer for the last 2 years before the diagnosis; currently changing jobs; undergoing treatment for 12 years.

Respondent 5 (Ewa): 44 years old, with higher education, divorced, bringing up 2 children, one of whom (the son) is disabled; breast cancer, treatment completed; works in her own catering service firm; did not stop working when she was diagnosed with cancer and carried on throughout her treatment; 2 years since completing treatment.

Respondent 6 (Maria): 49 years old, with higher education, married with 2 children; breast cancer, treatment completed; worked as a probation officer; currently (for half a year) working in a foundation assisting excluded persons; wants to change her job; 3 years since completing treatment.
The interviews were recorded and then transcribed. The interview analysis included the identification of the most frequently appearing groups of topics and motives. The identified issues were consulted with a competent judge and the final 4 motives were selected. The last phase involved selecting (together with the respondents) the titles/quotations that most accurately described their meaning.

\section{RESULTS}

\section{Motive 1. The meaning of work} "Despite people often complaining about work, they cannot go without it” (A. Kępiński)

Amost all the respondents emphasized that work was important primarily for economic reasons when responding to the following questions: What attitude to work did you have before your illness? Did you like your job? What motivated you to it? Thus, the subjective function of professional work was important, as a result of which an individual takes action to satisfy one's basic existential needs.

Violetta: "Work was really important to me. It was very important for several reasons. Also because I'm raising my son on my own and somewhere I had this load on my back all the time - 'no pain, no gain.' That's the way I was brought up. There's nothing without hard work. Well, for me, this responsibility for my child - because, of course, I wanted to provide as much as possible for him."

Maria: "Over the course of time, I mean, it gave me independence, a sense of some kind of comfort, financial security. It was very hard work, responsible, difficult. On top of that, I was working in a different town and would return to my husband for the weekend."

Edyta: "Thanks to work, I had money; we were independent. I was investing in myself, I finished university, and this gave me good earnings without struggling to make ends meet."

Ewa: "Was work important? It was the only source of maintenance for my family (...). I mean, it's not that I'm making any sacrifices, I wasn't losing, I wasn't losing myself. I mean, I still had time for myself, for the things I love doing."

Anna: "It's obvious that it provided our livelihood (...). I chose this work for myself so I just stuck with it, and it was difficult for me to take things and stop them. Well, it was important, because we've got many needs; my girls are still studying."

For the respondents, professional work was also a means of satisfying their ambitions, an affirmation of 
their competences, contact with other people - in other words, a source of self-realization.

Violetta: "I too found myself in such a moment in life that I wanted to have increasingly higher positions. And so I charged on, oblivious, full steam ahead. The corporation had sucked me in."

Maria: "I generally really liked my work at the beginning, that's what it was like. I really liked it and despite them sometimes saying 'What kind of job is that, especially for a woman?' that all the time you're moving in circles of people who break the law and have various problems, I felt good in it."

Ewa: "It was my life, a part of my life, it was. I'm a sole trader, I started out 5 years before my illness. It was important. When I opened my own business, things really changed in my life because I was running a business in which weekends, which had once been free and which I'd spent with my kinds, suddenly became even more busy with work (...). I'd work from Monday to Sunday, but I liked what I was doing."

Edyta: "I liked having contact with people, going out. Apart from that, I felt others needed me. My clients were usually older people, lost in official regulations (...). Helping them gave me a lot of satisfaction. I would often go beyond my duties but I liked devoting my time to them. Well, I felt I was needed. It's as simple as that."

Zofia: "I hadn't worked for a long time because of my illness and my husband earned good money abroad. I didn't have to work. But now I appreciate my work and how much it has changed things for the better. Because life has become, let's say, more valuable for me now that I'm working compared to the time when I wasn't. And even in such an ordinary life, when it comes to my daily schedule, how much everything is now ordered. The possibility for development, contact with other people, some kind of new duties, well, self-development, because every kind of work develops some competences, you acquire new skills and abilities..."

The lack of professional activity was felt as life wasted, a source of frustration and non-fulfillment. In Zofia's case, this led to a feeling of the aimlessness of life, and even marginalization.

Zofia: "I wasn't working before the illness. I've been undergoing treatment for 12 years now, non-stop (...). But I was worried that I wouldn't go to work because of my illness (...). I was wondering about my future, what it's going to look like exactly. I'm only 36 years old and I don't want the illness to somehow exclude me from professional life in the future. (...) My ex-husband, he really earned a lot, working abroad (...). Nobody encouraged me to take up this job. Everyone was telling me to rather focus on my health, that there would still be time for work, but that health is most important for now. I was continually having, every year in fact, for 6 years, operations (...), then some kind of treatment, and, well, I came to realize that a lot of this time was wasted - a kind of wasted life. Because it was this aimless going round in circles. Like that... and today, maybe I'll get up at 8:00, maybe at 10:00. Or maybe I'll do something; nah, I won't do that today... Maybe tomorrow. Maybe I won't be going out today and just be watching TV - all this simply aimless. The days passed, my life was slipping through my fingers."

\section{Motive 2. Work and the emergence of the illness "Life consists of setting the right proportion between work and rest" (J. Pilch)}

As a result of an oncological illness, many people want to sum up all the factors that could have contributed to its emergence. The surveyed women pointed out that, at a certain point in time, work became too much of a burden for them, the excessive amount of numerous duties started to weigh them down, leading to somatic symptoms and a decrease in their psychological well-being.

Maria: "However, with time, I was required to take on more and more duties. Because I already knew this work, because it wasn't a year or 2 of work, but many long years, and the duties just piled up. I wanted to get it all done, well, I wanted to do my job, it's as simple as that; and, unfortunately, it turned out, at a certain time, that I was just too tied up with all these duties. I generally had this power in me, this energy... A lot of it... And I noticed that the work was starting to be... let's put it differently, I wasn't getting any energy from work, but just losing it irrecoverably. And the more time passed, the worse it was. That's why I felt totally divest of strength (...). I wasn't considering changing jobs yet because I was simply afraid of losing this sense of security."

Ewa: "At a certain moment in time, this became too much for me already, since... putting it differently, I had a problem every year because I took out a loan for this business of mine; repayment of this credit was a burden for me. Particularly in the low season, because my work is linked to the seasons. This overwhelmed me and made me frustrated."

Violetta: "I was a little cog in a corporation (...). Thousands of kilometers covered, continually new tasks, having to be there at every beck and call. I didn't have any time for myself or for my son whom I bring up on my own. I was working right up to my operation 
and after the operation, without thinking that I deserve some time off. And my boss rang me and asked: 'when are you finally coming back to us because I don't have the strength to cover for you.' Nobody even asked how I was feeling, or whether I needed anything."

Maria: "Working the way I was, I completely lost touch of everything going on around me. I didn't even notice the changes in the seasons. I just saw that, well, I don't know, that it's warm or cold, and for me that meant to dress appropriately because that's what was required considering the weather. But, in general, my life was slipping though my fingers. And that's how my life was completely slipping by that I completely don't know where this time went (...). I also lost myself in all of this, my... sort of this inner strength that I practically don't know what is happening in my life."

Ewa: "For me, it certainly contributed to my spinal pain that I was feeling. Oh yes, but did it to the illness? I think that it may have, indirectly, contributed also to the illness. When we were talking in a group about work, it was clearly evident straight away in whom work was the cause of cancer. You can see it straight away, just like that. Then, the voice breaks straight away."

The respondents would often emphasize that the cancer illness was, in a sense, a salvation - a warning that they should change something in their professional life. The illness would many a time trigger the thought of "I don't want to live like this."

Violetta: "There came the illness and it changed a lot in my life, and I think that if it hadn't been for it, in all honesty, I actually don't know what would have happened to me. Because I felt that I was nearing some kind of verge, a kind of approaching the brink of something, I don't know... I was only living and breathing the corporation, travelling a lot across the country; I was in charge of huge projects. Constant stress, no time for myself, for my son... I don't know how it would have ended..."

Maria: "I can tell you straight away, yes, the cancer saved me. I don't know what would have happened; I think I would have died doing this job. It had taken everything away from me at a certain moment; it didn't give me anything back. This concerns the whole of my energy because, well, financially it's obvious that that's what we work for... To have money, which we need to function."

Anna: "My friends would tell me to give it up but I just stuck to it and, well, right now I can say that the illness was somehow a salvation from this because I don't know if I would have changed it myself. This work was my nightmare because of my boss, and it was too much for me physically, because it involved lifting, always in a newsagent's store. But I never had the courage to give it up because I was afraid that I wouldn't be able to find another job."

However, women do not always connect their professional work with the emergence of the illness. Some do not see such a relationship and even emphasize that professional activity was a factor that protected them against the stress of everyday life and problems.

Edyta: "Work always helped me get away from everyday problems and 'clear my head,' as they say."

Zofia: "I appreciate work and how much it has changed things for the better. Because life has become more, let's say, valuable now that I'm working (...). The opportunity to develop, have contact with other people, go out every day, take on some kind of new duties; well, flourishing as a person, because every job develops some kind of new competences, you acquire new skills and abilities (...). I don't know, I think somehow it too was important to me to achieve fulfillment, to live normally. Well, above all, what work gives is this escape from health problems. Because sitting at home and not working was conducive to continually thinking about being ill. Thinking about the future, what's going to happen next, what my life is going to look like in general..."

\section{Motive 3. Returning to professional activity "One should choose work much more carefully} than a spouse because that is where more of the time is going to be spent than in their company" (J. Carroll) After completing treatment, all the surveyed women wanted to take up work. Some of them had just changed jobs or were in the course of doing so. Others were on the searching stage. Each of them cherished the hope that the work performed by them would be a source of satisfaction and self-realization.

Maria: "I wouldn't want work to take my energy away, or siphon it off. I'm terribly afraid of this, so much that my voice is already... Now I've changed my job to a worse paid one. Earning 50\% less, I simply came to the conclusion that it's quid pro quo. I also don't have such inflated needs but, most of all, I want my new job, for it to not only be a means of sustenance (...) but I want to draw from this work and for it to give me satisfaction. I was also fed up with working out of home."

Zofia: "I changed jobs and I'm very pleased with this fact. My previous work was tiring and same old, same old; just very tedious and monotonous. And, well, I was also beginning to be affected by the push for results, simply put. Tables, sending out effectiveness sheets, comparisons 
between our group and other groups, tracking things all the time, having to chase things, chasing results all the time... Well, with time this too translated into stress. I would later re-live it all at home (...). I'm glad that I made this move to leave and I think that I'm going to learn something new, gain a new experience, new skills, and I simply really need this - to start doing something different, to develop. Now it's just same old, same old over again. The only goal is to simply sell the product."

Violetta: "I want to start my own business. I'm not after making a fortune and rolling in money, goodness knows what, but I'm after pleasure and worthwhile work. You know, I just think that when you're going back to work, you don't think that... I don't know... that you're in pain, that you've got aches and pains here and there, that... I don't know... that you should go to some doctor. I'm going to keep my mind occupied with work-related matters. I'm of the opinion that there has to be rest after treatment, to recover and regenerate. It seems to me that everyone should go back to work. Work means normality, it's a return and a different way of thinking about oneself, a different life."

Edyta: "I went back to my old job, I couldn't imagine doing any other job. But my boss encouraged me not to return yet because I could still go on rehabilitation benefits (...). This made me sad."

Anna: "I want to go back to work. Well, because this means that I'm in recovery from my illness and it's my comeback. Well, I don't really know how to call it... It is important. Work is precisely the determinant of this normal life, the life of healthy people. Sitting at home, I have thought many a time that I simply miss this work because, right from the morning, everybody's going to school or work. So, I'm thinking to myself that, simply put, this time is somehow slipping through my fingers, that I'd slowly like to go back to work. All in all, I like being in this direct contact with people and I'd like to return to this kind of work, it's just that - of course - to something less intense because, due to my illness, I'm no good when it comes to lifting things (...). I mean, I'm looking through job offers. I'd like to but I don't want to work in such conditions and in such an atmosphere as I did before the illness. If that would be the case, I'd prefer just staying at home."

\section{Motive 4. Support in the workplace "To have somebody who would understand me - this is my only need in life" (G.G. Marquez)}

The thread of their health situation not being understood by employers and fellow employees would often appear in the narratives of the surveyed women. The respondents also spoke of the lack of support from physicians and no career guidance counselors for the group of persons suffering from a chronic illness. Other people's anxiety when discussing the illness with them was also mentioned.

Anna: "I was working half a year after my illness but this was difficult. The people I was working with envied me that I only had $7 \mathrm{~h}$ of work, and that I couldn't clean or lift things. This wasn't cool at all. They would show me at every step of the way that it was a wonder why I was privileged. But nobody would ask about my illness."

Edyta: "As a person with a disability, I work $7 \mathrm{~h}$ /day. During these hours, I do everything that my colleagues do and even more, but my boss hasn't given me a raise, explaining this by me working for a shorter period of time. Anyhow, my friends also look at me tellingly in relation to me finishing work early. I had the urge to put up a notice above my desk 'you're jealous of my shorter working time? Go on then, have my disability."

Violetta: "Everything was fine when I was looking for work, right up to the time when I said that I was suffering from cancer... It's as though they were afraid..."

Anna: "At the job centre, there's no offer for people after cancer. Everyone's just eager to say that we should simply go on benefits."

Zofia: "The doctors are surprised that I want to work during my treatment. They can't put the two together that I need this, that I want to work."

Violetta: "You know what? I'm just thinking to myself that when you go back to work, you don't think that, well... you know... I'd like to set up this foundation that will help people find a job after having cancer treatment. Because, well, it seems to me that persons after cancer aren't that keen on going back to work. That's the way I see it. Those are my observations. And I'm thinking that many people don't want to go back to the same job or there's no room for them there, or they're afraid of how they're going to be perceived. I think that everyone should go back to work. Work means normality, a different way of thinking about oneself, a different life."

Ewa: "I can't allow myself not to work. I have a disabled son, a teenage daughter, a mortgage and loans, and no help from my former husband. But, for me, the situation was that I couldn't leave my firm during treatment. I had to drag myself from chemo and be in the firm. And now I think I miss this time out to be ill. But if you have your own company, you don't deserve anything, you don't have any help. That's just the way the regulations are." 
Edyta: "An employer, if they had no personal experiences with cancer, has no idea what kind of illness this is. You're back at work, so you're in good health, and if not, then go on benefits."

\section{DISCUSSION}

The diagnosis and treatment of an oncological illness result in a lengthy absence from professional life, lasting many months. For many people who are suffering from an illness, particularly those for whom professional life was a significant value, as well as for young people, returning to work after they complete their treatment is possible and even desirable for therapeutic reasons. However, it is often difficult due to either their long absence from their job or the scope of duties that their job entails. Thus, on occasion, an abrupt return to one's professional duties is often beyond the capabilities of the person concerned because they are incapable of overcoming various emerging difficulties that include health issues related to the previously undergone treatment. This leads to a number of psychological problems and underpins the decision to go on sickness benefits.

The problem of returning to work by convalescents is oftentimes treated marginally by physicians and psycho-oncologists [16]. The professional activity of a person suffering from cancer, going back to work, seems to be very important because alternatives to the socio-medical model are now being pursued. A stream of scientific thought has emerged objecting to treating an illness as a deviation, a disorder, a disruption or the end stage. It suggests treating an illness as an opportunity for personal development, as a situation that can inspire an individual to undertake creative work and effort to develop their own biography - a new vision of personal identity. The approach to this issue by Strauss, Charmaz, and Frankl [7,17], among others, draws attention to the agency of persons suffering from an illness and their potential to actively adjust to being chronically ill. This applies to such activities of ill persons that are geared towards repairing the "cracks" caused by the illness in their personal biography, also by way of developing new ways of perceiving one's "self." When analyzing the above-quoted respondent statements, their reflection is clearly visible on the very impact of work on their life and health, its significance in building the future, their dissension to work being a source of stress, frustration, and dissatisfaction and, in the assessment of some, a contributing factor to the emergence of their illness.
In the sociology of medicine, Frank [17], who himself experienced cancer, built the concept of a "remission society," whose members are persons who do not fit in the clear-cut dichotomy of being either completely healthy or ill. Within it, he examined an illness in the categories of change - a change of every aspect of life. This change consists in building new life values on the experience of a loss, and taking the risk of making a positive change. The surveyed women are clearly embedded in this concept, planning their lives "after cancer" - in this case, within the working life sphere. Almost all were ready for change in their life, underpinning and driving their self-realization, and giving them a sense of satisfaction and fulfillment.

\section{CONCLUSIONS}

Positive change in the life of a person suffering from an illness rests on carrying out specific, illness-inspired intellectual work. Based on the above deliberations, it may be concluded that the loss of professional activity is a very challenging experience for persons suffering from an illness, whose sense of self-worth is closely linked to their work. Cancer becomes a destructor of their socio-economic status and position.

Faced with cancer, the respondents often perceived professional work as a cancer activating factor. Thus, they gave a holistic, socio-ecological dimension to the causes of their illness. At the same time, they also claimed that professional activity might improve their quality of life, provided that the workplace was conductive to bio-psycho-social health.

All the surveyed women wanted to work, regardless of their current health situation and prognosis, emphasizing that professional work was incredibly important for them, not only for economic reasons but also in terms of their self-realization.

A person with a chronic illness like cancer is often incapable of carrying out the same job as before their illness or working full-time. What they need is flexible working time, and a gradually increasing working time and workload. Thus, they need emotional support from their supervisors and colleagues, alike. Therefore, education in the workplace concerning the functioning and needs of persons with chronic illnesses seems imperative.

When working with a person with cancer, it is worth considering the possibilities that returning to work is likely to carry. It is important to create such jobs and work environments that would be consistent with 
the concept of health promotion. It seems that the key factors here are the appointment of persons responsible for the return process of a person with a chronic illness, accompanied by efficient communication between the employer and occupational health services, and efficient exchange of information between the treating physician and the workplace (with the employee's consent).

The presented research shows how important professional work is in the situation of cancer. Undoubtedly, this problem is linked to the wide-ranging category of the "quality of life." Therefore, it seems necessary to continue research, with a deeper exploration of individual threads. Reflection on work in an oncological disease is related to the time before the disease (e.g., What did work "do to me"? or How did it contribute to the disease?); the stage of treatment and professional inactivity (e.g., Who am I while not being an employee?); the stage of return to work (e.g., How does my new identity after the disease fit into my new life? How am I perceived: different or alien?). It can, therefore, be said that the presented research and conclusions are only the first layer of reflection on the meaning and sense of professional work in the situation of cancer.

\section{REFERENCES}

1. Jassem J, Kordek M. Oncology. Gdańsk: Via Medica; 2019. p. 13.

2. Klimek R, Madej JM, Sieroń A. Cancer - Cancers and Oncological Diseases. Krakow: Wydawnictwo RK; 2006. p. 168.

3. Kleinman A. The Illness Narratives. Suffering. Healing and the Human Condition. New York: Basic Books Inc.; 1991. p. 3.

4. Strauss AL, Glaser BG. Chronic Illness and Quality of Life. St. Louis, Toronto: The C.V. Mosty Company; 1984. p. 1.

5. Nolte E, McKee M. Caring for People with Chronic Conditions: An Introduction. In: Nolte E, McKee M, editors.
Caring for People with Chronic Conditions. A Health System Perspective. Berkshire: MsGraw Hill, Open University Press; 2008. p. 1-14.

6. Skrzypek M. The Perspective of a Person with an Illness in Chronic Illness Sociology. Lublin: Wydawnictwo KUL; 2011. p. 62.

7. Giddens A. Sociology. Warsaw: Wydawnictwo Naukowe PWN; 2009. p. 29.

8. Pietrzyk A. That Illness in the Family. The Psychology of Cancer. Krakow: Wydawnictwo Impuls; 2006. p. 62.

9. The National Cancer Registry [Internet]. The Registry; 2020 [cited 2020 Jan 15]. Krajowy rejestr nowotworów. Available from: https://www.coi.pl/krajowy-rejestr-nowotworow.

10. Tamminga SJ, de Boer AG, Verbeek JH, Frings-Dresen $\mathrm{MH}$. Breast cancer survivors' views of factors that influence the return-to-work process - a qualitative study. Scand J Work Environ Health. 2012;38(2):144-54.

11. Nielsen AF, Zinckernage L, Tofte JB, Timm H. Cancer survivors on the process of returning to work: a Danish focus group study. Scand J Work Environ Health. 2012; 38(2):89-184.

12. Mazurkiewicz A. Women with breast cancer and their return to work. Oncol Clin Pract. 2009;5:14-9.

13. Simonton C. Getting Well Again. New York: Bantam Doubleday Dell Publishing: 1992.

14. Kacprzak K. Interpretative Phenomenological Analysis. The Characteristics of the Approach and Potential for Application in Pedagogy/Andragogy. Rocz Andragog. 2016;23:283-309.

15. Pietkiewicz I, Smith JA. A Practical Guide to Using Interpretative Phenomenological Analysis in Qualitative Research Psychology. Czas Psychol. 2012;18(2):361-9.

16. Simonton C. How to Live with Cancer and Overcome it. Łódź: Wydawnictwo Feeria; 2006.

17. Rogiewicz M, editor. A Practical Guide to Adult Psychooncology. Medycyna Praktyczna; 2015. p. 137-9.

18. Frank A. At the Will of the Body. Reflections of Illness. Boston-New York: A Mariner Book, Houghton Mifflin Company; 2002. p. 6.

This work is available in Open Access model and licensed under a Creative Commons Attribution-NonCommercial 3.0 Poland License - http://creativecommons.org/licenses/by-nc/3.0/pl/deed.en. 